\title{
Low density lipoprotein receptor-related protein 1 expression correlates with cholesteryl ester accumulation in the myocardium of ischemic cardiomyopathy patients
}

Roi Cal ${ }^{1}$, Oriol Juan-Babot ${ }^{1}$, Vicenç Brossa ${ }^{2}$, Santiago Roura ${ }^{3}$, Carolina Gálvez-Montón ${ }^{3}$, Manolo Portoles ${ }^{4}$, Miguel Rivera ${ }^{4}$, Juan Cinca ${ }^{2}$, Lina Badimon ${ }^{1,5}$ and Vicenta Llorente-Cortés ${ }^{1^{*}}$

\begin{abstract}
Our hypothesis was that overexpression of certain lipoprotein receptors might be related to lipid accumulation in the human ischemic myocardium. Intramyocardial lipid overload contributes to contractile dysfunction and arrhythmias in cardiomyopathy. Thus, the purpose of this study was to assess the effect of hypercholesterolemic LDL and hypertrigliceridemic VLDL dose on LRP1 expression in cardiomyocytes, as well as the potential correlation between LRP1 expression and neutral lipid accumulation in the left ventricle tissue from ischemic cardiomyopathy patients. Cell culture experiments include control and LRP1-deficient cardiomyocytes exposed to lipoproteins under normoxic and hypoxic conditions. Explanted hearts from $18 \mathrm{ICM}$ patients and eight non-diseased hearts (CNT) were included. Low density lipoprotein receptor-related protein 1 (LRP1), very low density lipoprotein receptor (VLDLR) and low density lipoprotein receptor (LDLR) expression was analyzed by real time PCR and Western blotting. Cholesteryl ester (CE), triglyceride (TG) and free cholesterol (FC) content was assess by thin layer chromatography following lipid extraction. Western blotting experiments showed that protein levels of LRP1, VLDLR and HIF-1a were significantly upregulated in ischemic hearts. Immunohistochemistry and confocal microscopy analysis showed that LRP1 and HIF-1 a were upregulated in cardiomyocytes of ICM patients. In vitro studies showed that VLDL, LDL and hypoxia exerted an upregulatory effect on LRP1 expression and that LRP1 played a major role in cholesteryl ester accumulation from lipoproteins in cardiomyocytes. Myocardial CE accumulation strongly correlated with LRP1 levels in ischemic hearts. Taken together, our results suggest that LRP1 upregulation is key for myocardial cholesterol ester accumulation in ischemic human hearts and that LRP1 may be a target to prevent the deleterious effects of myocardial cholesterol accumulation in ischemic cardiomyopathy.
\end{abstract}

Keywords: Ischemic cardiomyopathy, LRP1, VLDLR, HIF-1a myocardial lipid accumulation

\section{Introduction}

The ischemic condition caused by decreased coronary flow is one of the most important factors leading to heart failure. Under ischemic conditions the myocardium undergos lipid accumulation in animal models [1-3] and humans [4]. In the ischemic heart, lipid vacuoles have been located in the periphery of the risk area $[5,6]$. While some authors have proposed a cardioprotective role for

\footnotetext{
* Correspondence: cllorente@csic-iccc.org

${ }^{1}$ Cardiovascular Research Center, CSIC-ICCC, Hospital de la Santa Creu I Sant Pau, Sant Antoni Ma Claret, 167, 08025, Barcelona, Spain

Full list of author information is available at the end of the article
}

cytosolic lipids in the cardiomyocyte $[7,8]$, others associate this phenomena to lipotoxicity $[2,9]$. In fact, it has been consistently reported that intramyocardial lipid overload significantly contributes to contractile dysfunction [10] and arrhythmias [11]. Recent work from our group demonstrated that myocytes exposed to high very low density lipoprotein (VLDL) doses depicts intracellular accumulation of neutral lipids, downregulation of SERCA2 expression, reduction of calcium transient amplitude, and SR calcium loading. These effects were exacerbated by submitting the cultured myocytes to an hypoxic environment [12]. Remarkably, a high prevalence

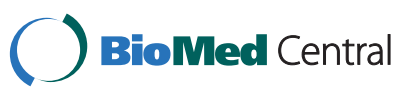


of fat deposition has been found in areas of chronic myocardial infarction in humans [4]. The patients with fat deposition had larger infarctions, decreased wall thickening and impaired endocardial wall motion [4].

It is known from several years ago that triglyceride (TG)-rich lipoproteins (chylomicrons and VLDL) supply both triglycerides and cholesteryl esters (CE) to the heart [13-15]. At present, the lipoprotein receptors involved in TG and/or cholesterol uptake by the cardiomyocyte remain largely unknown. Indeed, a basal expression of lipoprotein receptors is essential to guarantee a correct energetic supply for the heart since its inhibition causes a marked decline in cardial mechanical function [15]. However, the upregulation of several lipoprotein receptors, including very low density lipoprotein receptor (VLDLR) [16] or low density lipoprotein receptor related protein 1 (LRP1) [17], has been previously reported to induce neutral lipid accumulation in cardiomyocytes under ischemic conditions. Moreover, both VLDLR [16] and LRP1 $[17,18]$ share a HIF-1 $\alpha$-dependent mechanism of transcriptional activation by hypoxia in cultured cells. Our group has also shown that LRP1 expression and cholesteryl esters levels are found upregulated in the ischemic myocardium of an in vivo porcine model of acute myocardial infarction [17]. LRP1 is also upregulated by extracellular matrix-aggregated LDL in cultured human vascular smooth muscle cells and by hypercholesterolemia in the porcine vascular wall [19].

According to our previous work in this field, we hypothesized that LRP1 may be upregulated by lipids in cardiomyocytes playing a key role in the ischemiainduced neutral lipid accumulation in human heart. Thus, the purpose of this study was to assess the effect of hypercholesterolemic LDL and hypertrigliceridemic VLDL dose on LRP1 expression in cardiomyocytes, as well as the potential correlation between LRP1 expression and neutral lipid accumulation in the left ventricle tissue from patients with ischemic cardiomyopathy.

\section{Material and methods}

\section{Collection of human samples}

A total of 18 explanted human hearts from ischemic cardiomiopathy patients was collected and immediately processed. In particular, these patients were undergoing cardiac transplantation at Sant Pau Hospital, Barcelona and La Fe Hospital, Valencia. Clinical data, electrocardiogram, Doppler echocardiography, hemodynamic studies, and coronary angiography were available on all patients. All patients were functionally classified according to the New York Heart Association (NYHA) criteria, and were receiving medical treatment according to the guidelines of the European Society of Cardiology [20], with diuretics $90 \%$, angiotensin-converting enzyme inhibitors $87 \%$, $\beta$-blockers $50 \%$, aldosterone antagonists $70 \%$, digoxin $49 \%$ and statins $80 \%$.

Eight non-diseased hearts were also obtained from donors with neurological death caused by traffic accident. The hearts were initially considered for cardiac transplantation but were subsequently deemed unsuitable for transplantation either because of blood type or size incompatibility. All donors had normal LV function and no history of myocardial disease or active infection.

Transmural samples were taken from the infarct border zone, and were immediately stored at $-80{ }^{\circ} \mathrm{C}$. The project was approved by the local Ethics Committee (Biomedical Ethics Committee of "La Fe, Valencia" and "Sant Pau, Barcelona", Spain) and conducted in accordance with the guidelines of the Declaration of Helsinki. All patients gave written informed consent that was obtained according to our institutional guidelines.

\section{Tissue homogenization}

Frozen ventricular tissues $(25 \mathrm{mg})$ were pulverized using a mortar and a pestle in liquid nitrogen. Sample were then homogenized in TriPure isolation reagent (Roche Molecular Biochemicals) for total RNA and protein extraction according to manufacturer's instructions.

\section{HL-1 cardiomyocyte cell culture}

The murine HL-1 cell line was generated by Dr. W.C. Claycomb (Louisiana State University Medical Centre, New Orleans, Louisiana, USA) and kindly provided by Dr. U Rauch (Charité-Universitätmedizin Berlin). These cells show cardiac characteristics similar to those of adult cardiomyocytes. LRP1-deficient cardiomyocytes were generated as previously described [17]. Control and LRP1-deficient HL-1 cardiomyocytes were maintained in Claycomb Medium (JRH Biosciences, Lenexa, KS, USA) supplemented with $10 \%$ fetal bovine serum (FBS) (Invitrogen Corporation, Carlsbad, CA, USA), $100 \mu \mathrm{M}$ norepinephrine, 100 units $/ \mathrm{mL}$ penicillin, $100 \mu \mathrm{g} / \mathrm{mL}$ streptomycin, and L-Glutamine $2 \mathrm{mM}$ (Sigma Chemical Company, St. Louis, MO, USA) in plastic dishes, coated with $12.5 \mu \mathrm{g} / \mathrm{mL}$ fibronectin and $0.02 \%$ gelatin, in a $5 \%$ $\mathrm{CO}_{2}$ atmosphere at $37^{\circ} \mathrm{C}$.

\section{VLDL and LDL preparation}

Human VLDL $\left(\mathrm{d}_{1.019^{-}} \mathrm{d}_{1.019} \mathrm{~g} / \mathrm{mL}\right)$ and LDL $\left(\mathrm{d}_{1.009^{-}}\right.$ $\mathrm{d}_{1.063} \mathrm{~g} / \mathrm{mL}$ ) were obtained from pooled sera of normocholesterolemic volunteers. VLDL and LDL preparations were less than 24 hours old and without detectable levels of endotoxin (Limulus Amebocyte Lysate test, Bio Whittaker). Aggregated LDL (agLDL) was prepared by vortexing LDL in PBS at room temperature. The formation of LDL aggregates was performed as previously described [21-23]. The ultrastructure of agLDL obtained by vortexing was similar to that of LDL modified by versican [22], 
one of the main chondroitin sulfate proteoglycans structuring the arterial intima.

\section{Exposure of cardiomyocytes to VLDL and LDL under normoxic and hypoxic conditions}

Cells were exposed to normoxia $\left(21 \% \mathrm{O}_{2}\right)$ in a Nirco gas incubator with gas mixtures consisting of $74 \% \mathrm{~N}_{2}$ and $5 \% \mathrm{CO}_{2}$ or to hypoxia $\left(1 \% \mathrm{O}_{2}\right)$ in a Hypoxic/Anoxic Workstation: H35 (Don Whitley Scientific Ltd.) with $94 \% \mathrm{~N}_{2}$ and $5 \% \mathrm{CO}_{2}$. Lipoproteins were added and maintained for the last 12 hours of exposure to normoxic or hypoxic conditions (24 hours). Cells were then harvested in TriPure Reagent (Roche) for PCR and Western blot analysis or in $\mathrm{NaOH} 0.1 \mathrm{M}$ for lipid extraction and thin layer chromatography.

\section{RNA extraction and cDNA synthesis}

Total RNA was extracted from fresh frozen tissue or cultured HL-1 cardiomyocytes using TriPure isolation reagent (Roche Molecular Biochemicals) and the RNeasy mini kit (Qiagen, Hilden, Germany) according to manufacturer's instructions. Extracted RNA was eluded in 25 $\mu \mathrm{L}$ of nucleases-free water. RNA yield and quality were assessed by agarose electrophoresis and spectrophotometry, and then stored at $-80^{\circ} \mathrm{C}$ until was used. RNA was digested with DNase I (Invitrogen). One $\mu \mathrm{g}$ of total RNA was used for cDNA synthesis according to the protocol provided with the HighCapacity cDNA Reverse Transcription kit (Applied Biosystems, Foster City, CA, USA). Recombinant RNasin Ribonuclease Inhibitor (Applied Biosystems) was added to prevent RNase-mediated degradation. The cDNA was also stored at $-20 \mathrm{C}$.

\section{Gene expression analyses by RT-PCR}

Gene expression analyses of $L R P 1, V L D L R$, and $L D L R$ mRNA were performed at mRNA level by quantitative real-time reverse transcriptase-polymerase chain reaction (q-RT-PCR). Specific primer and fluorescent TaqMan probe for $L R P 1, V L D L R$ and $L D L R$ were selected within a list of predesigned assays (Assays-on-Demand LRP1 (Hs00233999_m1), VLDLR (Hs01045922_m1) and LDLR (Hs00181192_m1) (Applied Biosystems). 18srRNA (4319413E) was used as a housekeeping gene. We mixed $5 \mu \mathrm{l}$ of single-stranded cDNA (equivalent to $100 \mathrm{ng}$ of total RNA) with $1 \mu$ l of 20x TaqMan Gene Expression Assays for each Assay-on-Demand, $10 \mu \mathrm{l}$ of TaqMan Universal PCR Master Mix, and $4 \mu$ l of nucleases-free water. After gentle mixing, the mixture was transferred into a real-time PCR microplate. The Real-time PCR microplate was sealed, centrifuged, and then was placed in the sample block of an Applied Biosystems 7300 Real Time PCR System (Applied Biosystems). The thermal cycling conditions were $2 \mathrm{~min}$ at $50^{\circ} \mathrm{C}$ and $10 \mathrm{~min}$ at $95^{\circ} \mathrm{C}$, followed by 40 cycles of $15 \mathrm{~s}$ at $95^{\circ} \mathrm{C}$ and $1 \mathrm{~min}$ at $60^{\circ} \mathrm{C}$. Expression levels were measured in triplicate. The threshold cycle $(\mathrm{Ct})$ values were normalized to the housekeeping gene $[17,18]$.

\section{Western blotting}

Total protein was extracted from fresh frozen tissue or HL-1 cell cultures using TriPure isolation reagent (Roche Molecular Biochemicals). Proteins were analyzed by Western blot analysis as previously described $[17,18]$. Blots were incubated with monoclonal antibodies against human LRP1 ( $\beta$-chain, clone 8B8 RDI 61067), VLDLR (Santa Cruz Biotechnology, Inc, D-17, sc-11823), HIF-1 $\alpha$ (Santa Cruz Biotechnology, H-206, sc-10790), LDLR (Epitomics, EP1553Y, 1956-1), VEGF (Santa Cruz Biotechnology, Inc, A2611, sc-152) and mouse monoclonal anti-Troponin T (Thermo scientific MS-295). Equal protein loading in each lane was verified staining filters with Pounceau and also by incubating blots with monoclonal antibodies against $\beta$-actin (Abcam, ab8226).

Lipid extraction and semi-quantitative analysis of cholesteryl ester, free cholesterol and triglyceride content of cardiomyocytes and myocardium

HL-1 cardiomyocytes were exhaustively washed and harvested in $\mathrm{NaOH} 0.1 \mathrm{M}$ following the lipoprotein

Table 1 Clinical and echocardiographic characteristics from whom explanted ischemic hearts were obtained

\begin{tabular}{|c|c|}
\hline & $\operatorname{ICM}(n=18)$ \\
\hline Age (years) & $54.53 \pm 2.67$ \\
\hline Gender male (\%) & $93 \%$ \\
\hline Prior hypertension (\%) & 46 \\
\hline Diabetes mellitus (\%) & 27 \\
\hline Obesity (\%) & 20 \\
\hline Total cholesterol (nmol/L) & $3.90 \pm 0.28$ \\
\hline Perfusion abnormalities* (\%) & $67 \%$ \\
\hline \multicolumn{2}{|l|}{ Echo-Doppler study } \\
\hline Ejection fraction (\%) & $25.86 \pm 1.80$ \\
\hline Intraventricular septum in diastole (mm) & $11.08 \pm 0.47$ \\
\hline Left ventricular posterior wall in diastole (mm) & $9.67 \pm 0.62$ \\
\hline Left ventricular end-diastolic diameter (mm) & $67.00 \pm 2.45$ \\
\hline Left ventricular end-systolic diameter (mm) & $58.50 \pm 3.94$ \\
\hline \multicolumn{2}{|l|}{ Treatment (\%) } \\
\hline Diuretics & 90 \\
\hline Angiotensin-converting enzymes inhibitors & 87 \\
\hline$\beta$-blockers & 50 \\
\hline Aldosterone antagonist & 70 \\
\hline Digoxin & 49 \\
\hline Statins & 80 \\
\hline
\end{tabular}

ICM, ischemic cardiomyopahhy; ${ }^{*}$ the patients with perfusion abnormalities were considered those subjected to coronary interventions (i.e. by-pass, angioplasty, stents and others). 
incubation period. In the animal experimental model, one portion of myocardial tissue $(5 \mathrm{mg})$ was also homogenized in $\mathrm{NaOH} 0.1 \mathrm{M}$. Lipids were extracted as previously described $[17,18]$ and $\mathrm{CE}, \mathrm{FC}$ and TG content was analyzed by thin layer chromatography.

The organic solvent was removed under an $\mathrm{N}_{2}$ stream, the lipid extract redissolved in dichloromethometane and one aliquot was partitioned by thin layer chromatography (TLC). TLC was performed on silica G-24 plates. The different concentrations of standards (a mixture of cholesterol, cholesterol palmitate, triglycerides, diglycerides and monoglycerides) were applied to each plate. The chromatographic developing solution was heptane/diethylether/acetic acid (74:21:4, $\mathrm{vol} / \mathrm{vol} / \mathrm{vol})$. The spots corresponding to cholesteryl esters (CE), triglycerides (TG) and free cholesterol (FC) were quantified by densitometry against the standard curve of cholesterol palmitate, triglycerides and cholesterol, respectively, using a computing densitometer.

\section{Immunohistochemical analysis}

Hearts were obtained from human transplant operations. Immediately after surgical excision, myocardium was cut in appropriated blocks. Myocardial tissues were immersed in fixative solution ( $4 \%$ paraformaldehyde), embedded in paraffin, cut into $5 \mu \mathrm{m}$ thick serial sections and placed on poly-L-lysine coated slides. The primary antibodies were rabbit monoclonal anti-LRP1 (Epitomics 2703 dilution 1:100), mouse monoclonal anti-Troponin $\mathrm{T}$ (Thermo scientific MS-295, dilution 1:100) and mouse monoclonal anti-HIF-1 $\alpha$ (Novus NB100-105, dilution 1:50). Antigen retrieval was required before performing immunohistochemical staining of Troponin T and HIF-1 $\alpha$. In a set of experiments, before incubation with primary antibody ( 2 hours), sections were washed and endogenous peroxidase activity suppressed with $\mathrm{H}_{2} \mathrm{O}_{2}$. Non-specific binding was blocked with an appropiate serum. The primary antibodies were detected using the avidin-biotin immunoperoxidase technique. The sections were incubated with an appropriate biotinylated secondary antibody (1:200, Vector $\left.^{\circledR}\right)$. 3,3'-diaminobenzidine-haematoxylin chromogen was used for nuclear stain. The images were captured by Nikon Eclipse 80i microscope and digitized by Retiga 1300i Fast camera. Magnification (240X).

In other set of experiments, cryosections were subsequently incubated with a Cy3-conjugated secondary antibody (Jackson Immuno Research Laboratories) at $37{ }^{\circ} \mathrm{C}$ for $1 \mathrm{~h}$. Slices were finally counterstained for 10 min with Hoechst 33342 (Sigma), and analyzed under a TCS SP5 confocal microscope (Leica).
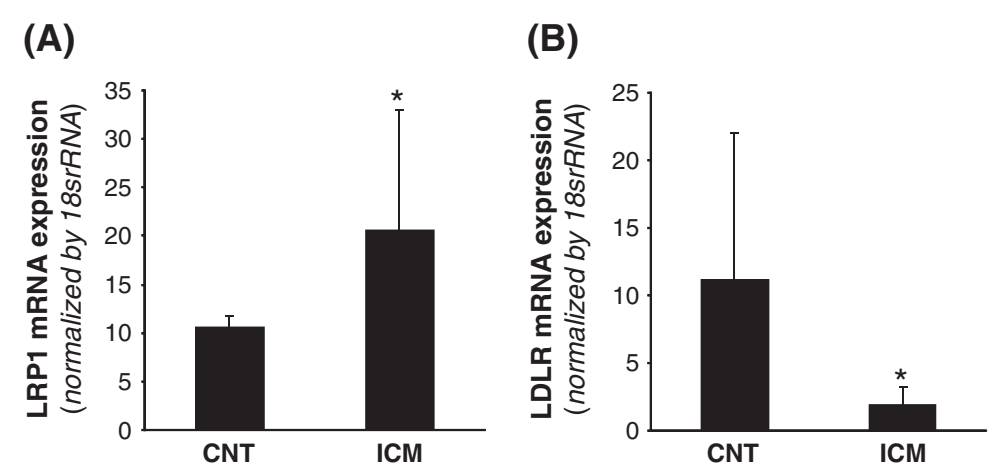

(C)

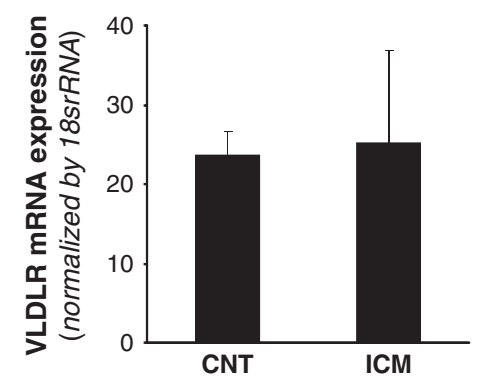

Figure 1 LRP1, VLDLR and LDLR mRNA expression in control and ICM hearts. Frozen myocardial tissue (5 mg) was homogenized in Tripure reagent and RNA isolated as explained in Methods. LRP1 (A), LDL receptor (B) and VLDLR (C) mRNA expression levels were analyzed by real time PCR. Data were processed with a specially designed software program based on Ct values of each sample and normalized to 18srRNA as endogenous control. ${ }^{*} P<0.05$ versus CNT. CNT, controls; ICM, ischemic cardiomyopathy patients. 


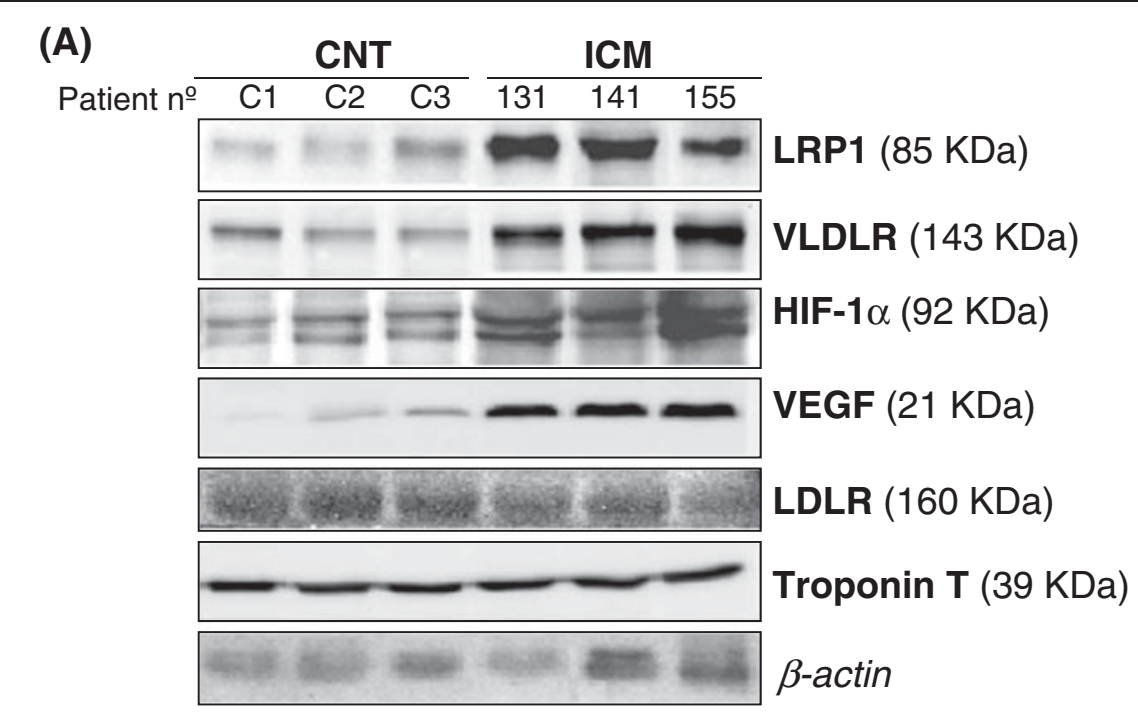

(B)

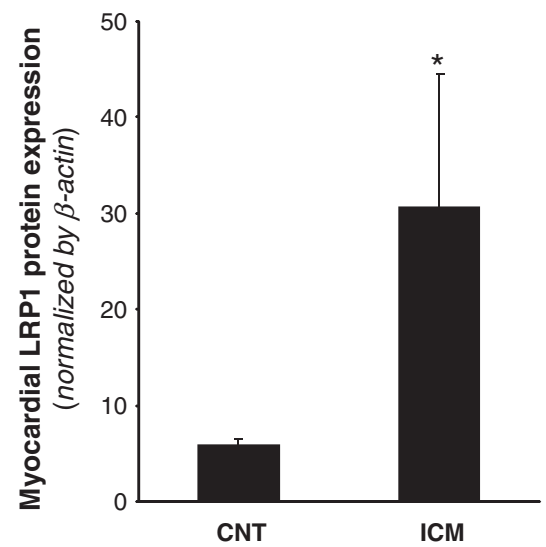

(D)

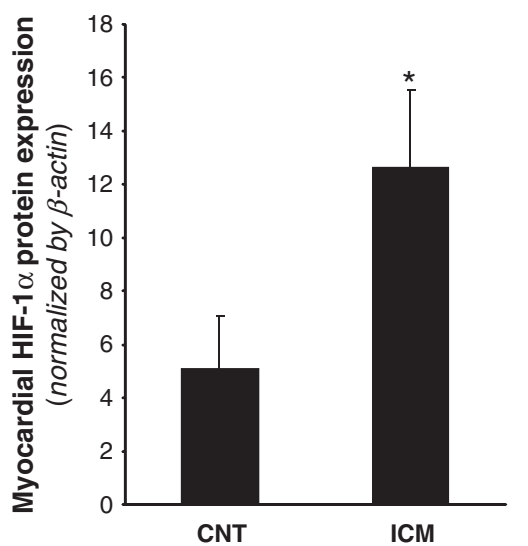

(C)

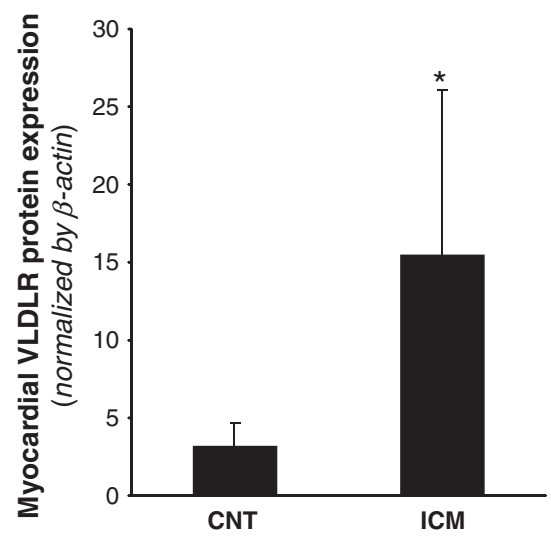

(E)

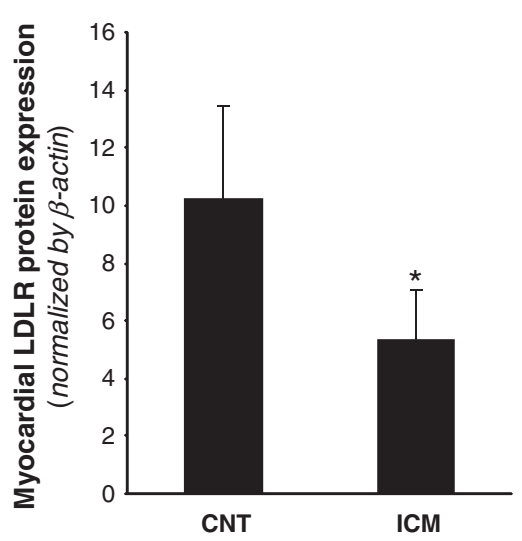

Figure 2 LRP1, VLDLR and LDLR protein levels in control and ICM hearts. Representative Western blot analysis (A) showing LRP1, VLDLR, HIF-1a, VEGF, LDLR and troponin T protein expression in three controls and three ICM patients. Bar graphs showing the mean \pm SD of protein LRP1 (B), VLDLR (C), HIF-1a (D) and LDLR (E) band quantification. Unchanged levels of $\beta$-actin were shown as loading control and used to normalize protein bands. ${ }^{*} P<0.05$ versus $C N T$. CNT, controls; ICM, ischemic cardiomyopathy patients. 


\section{Statistical analysis}

Results are expressed as mean \pm standard deviation (SD). Statistical significance between groups was analyzed by one-way analysis of variance (ANOVA) followed by a post-hoc Tamhane test. Correlation analysis was performed according to Pearson. Statistics were calculated using Statistical software package Statview (SPSS) for Windows. A value of $P<0.05$ was considered significant.

\section{Results}

\section{Clinical characteristics of patients}

The clinical and echocardiographic characteristics of patients are summarized in Table 1. These patients were all symptomatic, had a NYHA functional classification of III-IV and were previously diagnosed with significant comorbidities including hypertension, hypercholesterolemia, obesity, and diabetes mellitus. Patients (93\%) were mostly men with a mean age of $54.53 \pm 2.67$ years and had at least one vessel affected by atherosclerosis. Left ventricular end-diastolic diameter was $67.00 \pm 2.45$. Eight non-diseased donor hearts were used as control (CNT) (60\% male, mean age $55 \pm 3$ years, and EF > $50 \%$ ). A high percentage of patients $(67 \%)$ were subjected to reperfusion techniques, also indicative of peri-infarct ischemia.

\section{Myocardial lipoprotein receptor expression}

LRP1 expression was analyzed at mRNA level by real time PCR and at the protein level by Western blot analysis from the same sample. As shown in Figure 1A, LRP1 mRNA expression was significantly higher in ICM than in control group (ICM: $20.57 \pm 12.41$ vs CNT: $10.66 \pm 1.13, P<0.05)$. In contrast, LDLR mRNA expression (Figure 1B) was significantly lower in ICM compared to controls (ICM: $1.89 \pm 1.29$ vs CNT: $11.14 \pm 10.90$, $P<0.05)$. No differences were found in VLDLR mRNA expression between controls and ICM hearts (Figure $1 \mathrm{C}$ ).

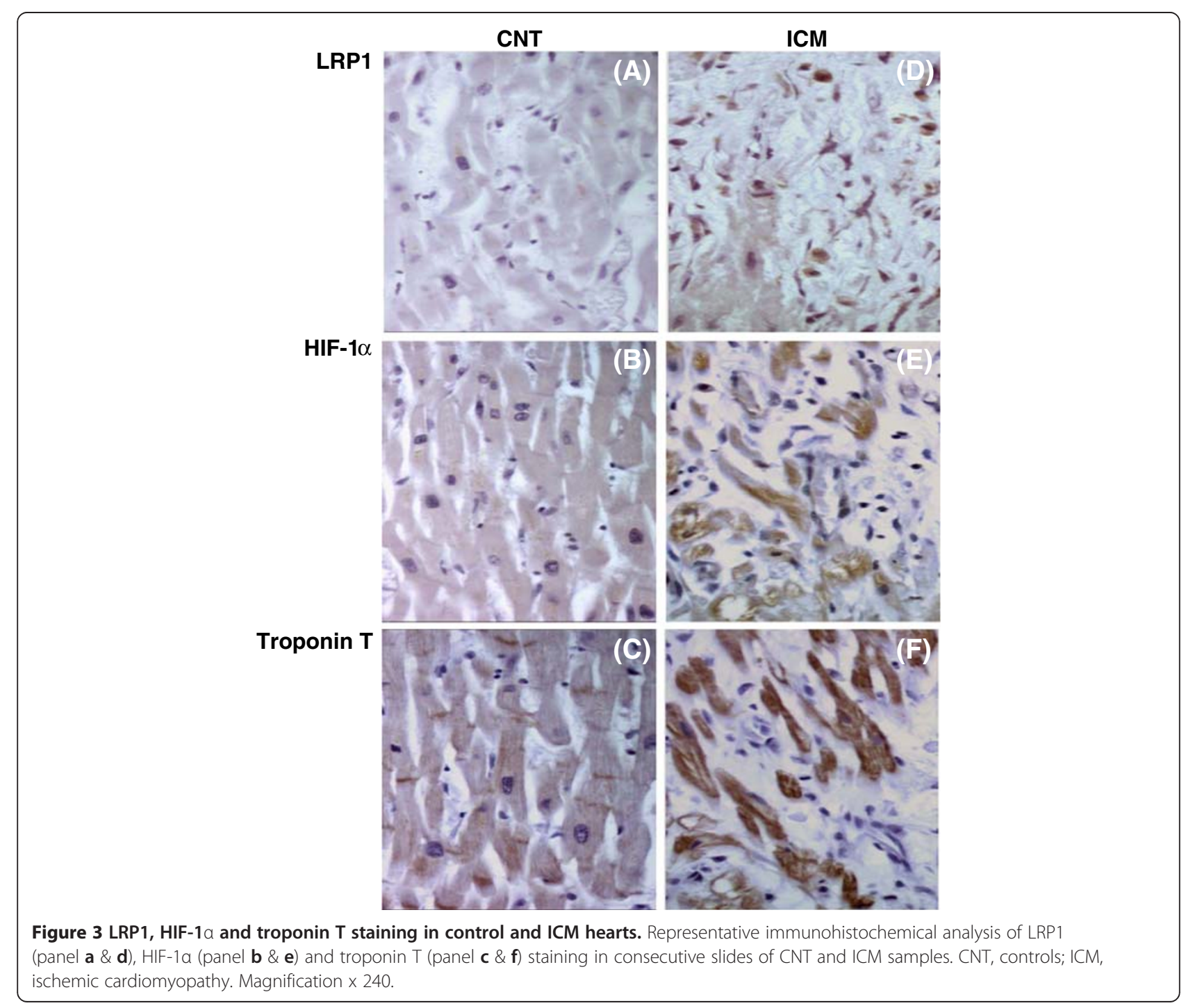




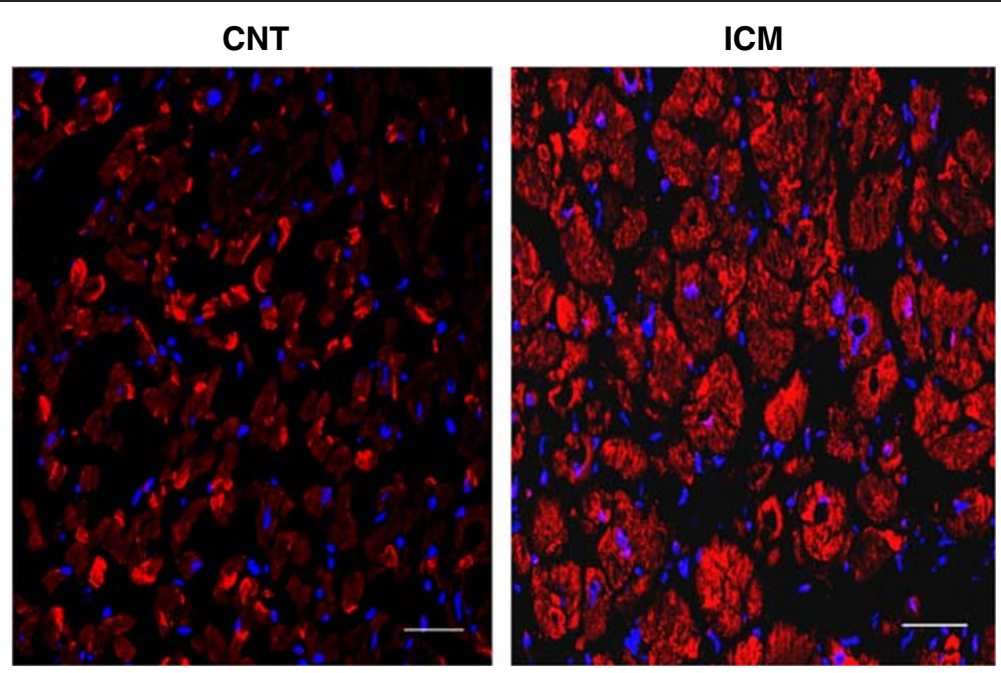

Figure 4 Confocal microscopy analysis of LRP1 expression in control and ICM hearts. Representative confocal microscope images showing specific LRP1 detection in myocardium from one ICM patient subjected to reperfusion and one from a control subject. Nuclei were counterstained with Hoechst 33342 (blue). Scale bars $=50 \mu \mathrm{m}$ (magnification x 400).

In agreement with real-time PCR data, Western blot analysis showed that LRP1 protein expression was significantly higher in ICM than in CNT hearts (ICM: $30.62 \pm 13.93$ vs CNT: $5.92 \pm 0.66, P<0.05$ ) (Figure $2 \mathrm{~A} \&$ B). Additionnally, VLDLR protein expression was significantly upregulated in ICM compared to CNT samples (ICM: $15.48 \pm 10.62$ vs CNT: $3.68 \pm 2.98, \quad P<0.05$ ) (Figure 2A \& C). In order to know whether HIF-1 $\alpha$ transcription factor may play a role on lipoprotein receptor upregulation in ICM samples, we analyzed HIF- $1 \alpha$ protein levels by Western blotting and used VEGF as a positive control. HIF-1 $\alpha$ protein levels were significantly higher in ICM in comparison with CNT hearts (ICM: $12.63 \pm 2.92$ vs CNT: $5.11 \pm 1.97, P<0.05$ ) (Figure $2 \mathrm{~A} \&$ D), as well as VEGF significantly increased in ICM samples. In contrast to LRP1 and VLDLR, LDLR protein expression was significantly lower in ICM samples (Figure 2A \& E).

Immunohistochemical analysis (Figure 3A) showed that LRP1 (panel a) and HIF-1 $\alpha$ (panel b) staining were
(A)
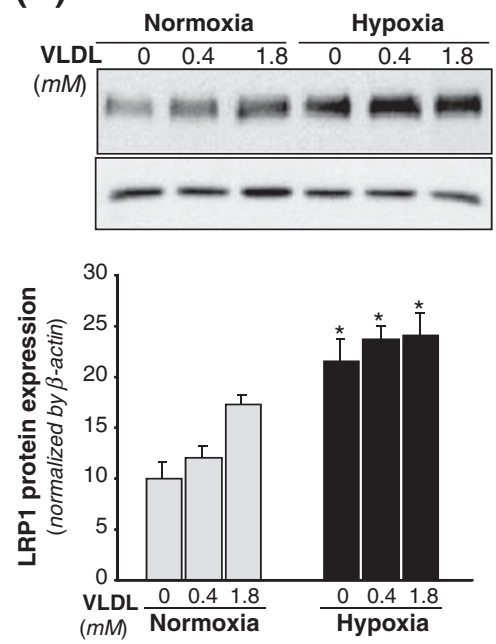

(B)
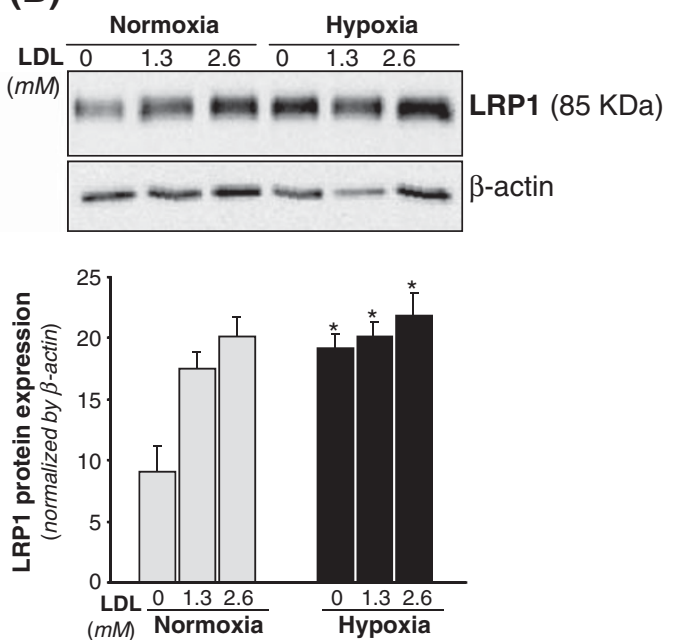

Figure 5 Dose-dependent changes of LRP1 protein levels in cardiomyocytes exposed to VLDL or LDL under normoxic or hypoxic conditions. $\mathrm{HL}-1$ cardiomyocytes were submitted to normoxia or hypoxia for 24 hours either in absence or presence of increasing dose of VLDL (A) or LDL (B) for the last 12 hours. Representative Western blot analysis showing LRP1 bands. Unchanged levels of $\beta$-actin were shown as loading control and used to normalize LRP1 bands. Results were shown as mean \pm SEM of three independent experiments performed in duplicate. ${ }^{*} P<0.05$ versus normoxic cells. \# $P<0.05$ versus cells incubated in absence of lipoproteins. 
undetectable within control myocardium. On the contrary, there was a positive staining for LRP1 (panel d) and HIF-1 $\alpha$ (panel e) in the myocardium of ICM patients. Confocal microscopy showed higher cardiomyocyte LRP1 staining in ICM patients compared to control subjects (Figure 4).

\section{Effect of VLDL and LDL on LRP1 protein expression in} cardiomyocytes under normoxic and hypoxic conditions VLDL (1.8 mM) (Figure 5A) and LDL (2.6 mM) (Figure $5 \mathrm{~B}$ ) significantly increased LRP1 protein by 1.72 fold and 2-fold, respectively. Hypoxia per se also exerted a significant upregulatory effect on LRP1 expression in HL-1 cardiomyocytes in agreement with previous results [17]. Previous studies from our group showed that LRP1 play a key role for aggregated LDL (agLDL) uptake in human vascular smooth muscle cells [21-23]. To know whether LRP1 may also take modified lipids in cardiomyocytes, we exposed control and LRP1-deficient cardiomyocytes [17] to agLDL. As shown in Figure 6, LRP1 deficiency significantly decreased the strong intracellular $\mathrm{CE}$ accumulation (65 $\pm 3 \mu \mathrm{g} \mathrm{CE} / \mathrm{mg}$ protein) derived from agLDL $(0.6 \mathrm{mM})$ in HL-1 cardiomyocytes. In contrast, LRP1 deficiency did not influence the slight intracellular CE $(10.6 \pm 0.2 \mu \mathrm{g} \mathrm{CE} / \mathrm{mg}$ protein) induced by native LDL $(0.6 \mathrm{mM})$ in cardiomyocytes.

\section{Myocardial neutral lipid content and correlation with lipoprotein receptor expression}

Myocardial lipid content was analyzed by thin layer chromatography following lipid extraction. Figure 7 shows representative CE, TG and FC bands from ICM patients and controls. Both myocardial CE (ICM: 92.2 \pm 68.3 vs CNT: $39 \pm 18, P<0.05$ ) and TG (ICM: $100.2 \pm 44.4$ vs CNT: $50.8 \pm 39.4, \quad P=0.04)$ content was significantly increased in ICM vs CNT. FC content of myocardium was unaltered by disease.

Myocardial CE strongly correlated with LRP1 mRNA $\left(\mathrm{R}^{2}=0.74, P<0.0001\right)$ (Figure $8 \mathrm{~A}$ ) and LRP1 protein expression $\left(R^{2}=0.72, P<0.0001\right)$ (Figure $8 B$ ). Although to a minor extent, myocardial $\mathrm{CE}$ also correlated with VLDLR protein expression $\left(R^{2}=0.398, P<0.012\right)$. In contrast, myocardial TG content did not show any correlation with LRP1 mRNA or protein expression.

\section{Discussion}

Taken together, our results demonstrate for the first time that myocardial LRP1 expression and cholesteryl ester content appear strongly increased and interrelated in the myocardium of ischemic cardiomyopathy patients. In particular, we show that LRP1 is upregulated in ischemic human hearts at mRNA and protein levels, although to a different extent. This difference in the quantitative modulation of LRP1 at mRNA and protein levels by

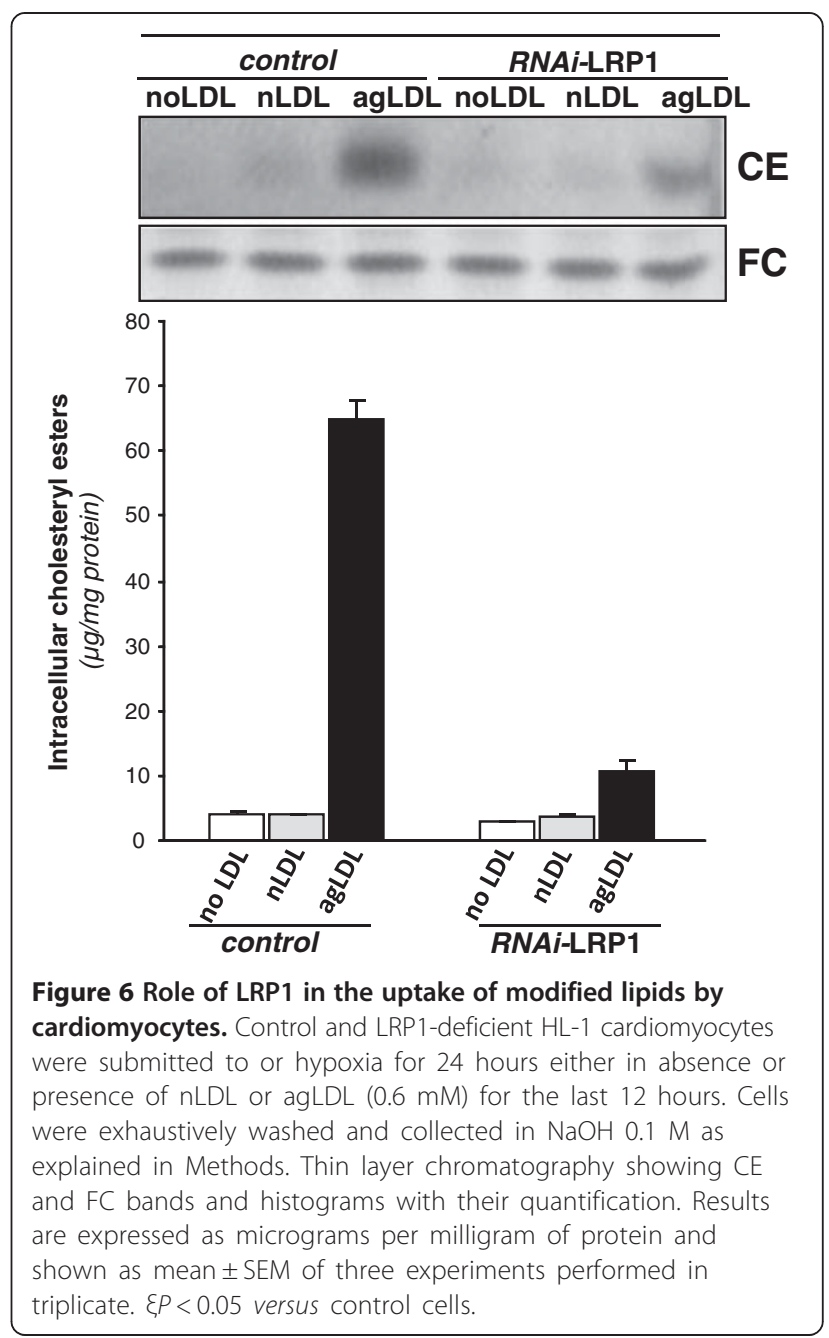

hypoxia has been previously shown in human VSMC and it may be explained at least in part by the long halflife time of LRP1 protein [18].

The upregulation of HIF- $1 \alpha$ protein levels in ICM hearts suggests that in patients, as previously shown in cultured cardiomyocytes [17] and vascular cells [18], HIF- $1 \alpha$ may participate in myocardial LRP1 upregulation in ischemic hearts. However, further studies are required to know the precise role of HIF-1 $\alpha$ on myocardial LRP1 overexpression in ischemic cardiomyopathy. In the group of patients included in this study, there was a high percentage of those with documented perfusion abnormalities, indicative of peri-infart ischemia. Moreover, enrolled patients had at least one vessel affected by atherosclerosis. Therefore, cardiovascular risk factor such as hypercholesterolemia or hypertension likely modulate LRP1 expression in the myocardium, as previously reported by our group in the vascular wall [19,24-26]. Indeed, the presented results demonstrate that high VLDL and LDL dose strongly increased LRP1 protein levels in cardiomyocytes. 

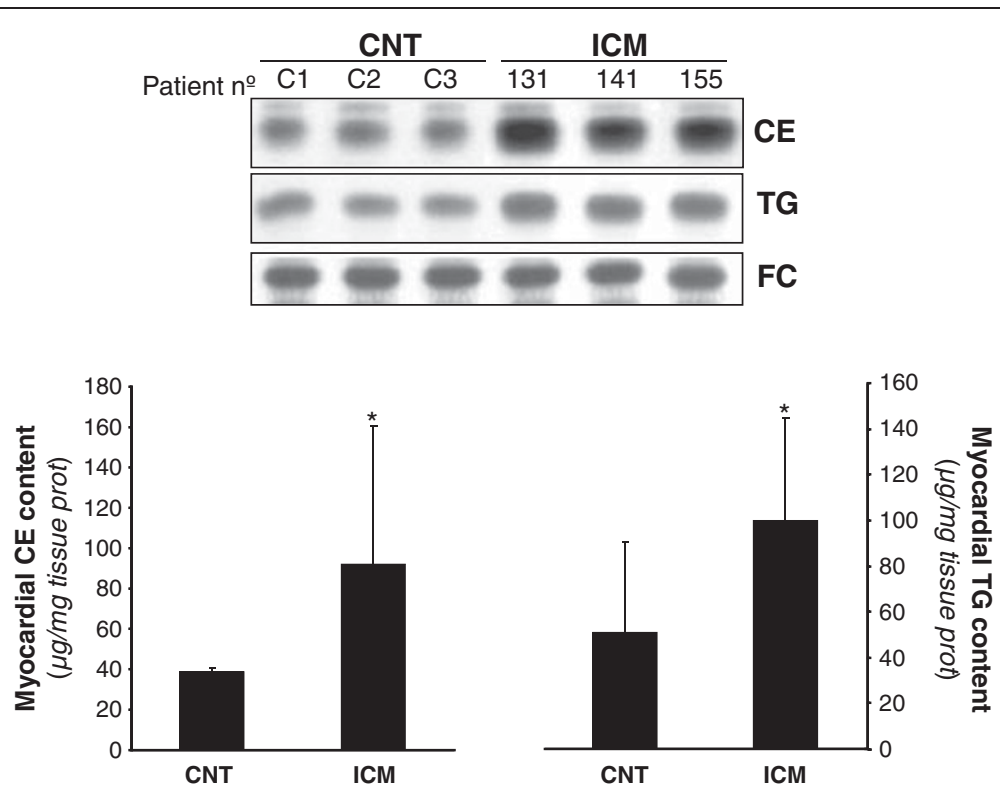

Figure 7 Myocardial cholesteryl ester (CE), triglyceride (TG) and free cholesterol content (FC) in controls and ICM hearts. Representative thin layer chromatography showing CE, TG and FC bands in three control and three ICM patients, and bar graphs showing the mean \pm SD of myocardial colesteryl ester and triglyceride bands in CNT $(n=8)$ and ICM $(n=18)$ groups. CNT, controls; ICM, ischemic cardiomyopathy. Results are expressed as micrograms per mg of tissue.

Ischemia has been reported to upregulate VLDLR expression in cultured cardiomyocytes $[12,16]$ and mice [16]. We also found VLDLR protein overexpressed in a porcine model of acute myocardial infarction [17] and in human ischemic hearts. Although VLDLR has been reported to be upregulated at mRNA level in myocardial biopsies taken from patients scheduled for coronary bypass surgery [16], we did not observe alterations of mRNA VLDLR expression levels in explanted hearts from ICM patients. It has been previously suggested that cyclosporine, an immunosuppressant used for the treatment of transplant recipients, inhibits VLDLR mRNA expression in the myocardium of ischemic cardiomyopathy patients [16]. In contrast to LRP1 expression, LDLR mRNA expression was lower in ischemic hearts compared to controls in agreement with our previous results in hypoxic cardiomyocytes [12,17] and vascular cells [18], suggesting that the classical LDLR plays no role in the neutral lipid accumulation associated to ischemic myocardium.

A significant finding of this study is the close association between LRP1 expression and cholesteryl ester accumulation in ischemic human hearts. Although this study does not provide information about the mechanisms involved in the link between LRP1 expression and CE accumulation, previous studies in our group have shown that LRP1 plays an essential role in the selective VLDL-cholesteryl ester uptake by hypoxic cardiomyocytes [17]. Additionnally, results from the present study show that cardiomyocyte LRP1, as vascular LRP1 [21-23],

\section{(A)}

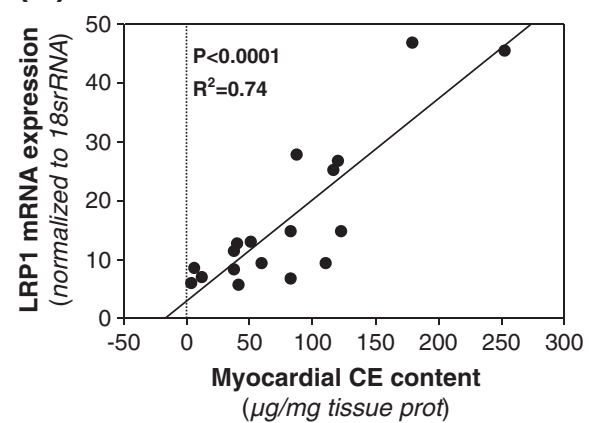

(B)

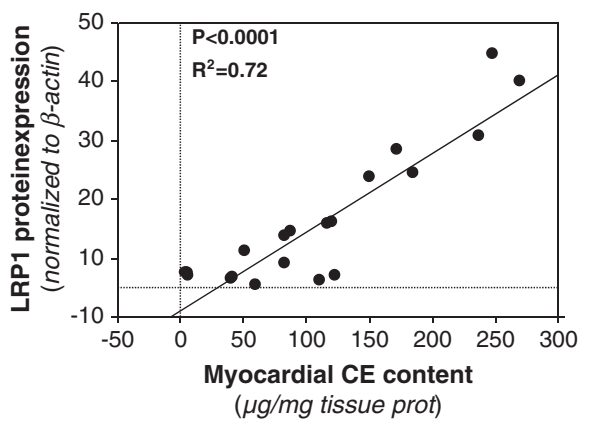

Figure 8 Correlation between LRP1 and CE content in the myocardium of ischemic cardiomyopathy patients. Analysis of correlation between myocardial cholesteryl ester content and LRP1 mRNA (A) or LRP1 protein (B) expression in ischemic cardiomyopathy patients ( $n=18)$. 
internalizes cholesteryl esters from modified lipoproteins. Taken together, these results support that $\mathrm{CE}$ overaccumulation in human ischemic hearts may be caused by the capacity of LRP1, when overexpressed by hypoxia, to take up cholesterol from lipoproteins. Previously, it has been shown that increased expression of VLDLR is essential for the accumulation of triglycerides in hypoxic cardiomyocytes and ischemic myocardium in mice [16]. These authors also found a slight but significant correlation between VLDLR mRNA and ORO staining. Here, we found that VLDLR, although to a minor extent that LRP1 expression, also correlated with CE accumulation in ischemic heart. In contrast, we did not observe any significant correlation between LRP1 or VLDLR expression and myocardial TG content. This lack of correlation may be related to the multiple pathways that influence myocardial TG content, that may derive from endogenous synthesis $[27,28]$, diffusion of albuminassociated fatty acids [29] or lipoprotein-TG-hydrolysis by LpL $[30,31]$.

In addition, also in agreement with our previous studies in vitro [12,17] and in vivo [17], we evidenced that in the myocardium of ischemic cardiomyopathy patients there was not only triglyceride but also cholesteryl ester accumulation. This is an interesting observation since most of the previous studies assumed that myocardial neutral lipid accumulation consist only in triglycerides $[1-3,16]$. Indeed, a precise knowledge about the mechanism of myocardial lipid uptake is required to prevent the deleterious consequences of this process in cardiac functionality.

\section{Limitations and considerations of the study}

The complexity of cardiomyopathy and heart failure originated by myocardial infarction cannot be afforded by testing the effect of hypoxia $\left(1 \% \mathrm{O}_{2}\right)$ in cultured cardiomyocytes or the effect of coronary occlusion on porcine myocardial gene expression. However, these in vitro and in vivo models have been useful to identify new genes involved in pathophysiological mechanisms underlying the deleterious effect of hypoxia on cardiac function. Recently, our group has previously identified LRP1 as key receptor for cholesteryl ester accumulation in hypoxic cardiomyocytes and ischemic porcine myocardium [17]. Results from the present study show that there is a strong LRP1 upregulation that significantly correlates with cholesteryl ester accumulation in ischemic cardiomyopathy patients. Therefore, our results suggest that cardiac alterations associated to the deleterious effects of myocardial cholesterol accumulation may be modulated through LRP1 targeting in heart failure and cardiomyopathy.

The clinical consequences of lipid accumulation under ischemia have not been directly addressed in this study but it is known that there is a close association between CE content of sarcoplasmatic reticulum and SERCA-2 suppression [32]. Additionally, hypercholesterolemia exacerbates myocardial necrosis and apoptosis in the setting of ischemia-reperfusion [33]. It is also known that hypoxia exerted a downregulatory effect on SERCA2 expression through HIF-1 $\alpha$ [34]. Our group demonstrated that hypoxia exacerbates the alterations in calcium handling induced by VLDL through potentiation of SERCA2 downregulation [12], and that the percentage of waves was reduced in calcium-overloaded-LRP1-deficient cardiomyocytes under stimulation. Taken together, our results consistently point out that LRP1 is a potential molecular target to prevent myocardial CE accumulation, and thus the cardiac alterations induced by cholesterol loading in ischemic cardiomyopathy.

\section{Competing interests}

The authors declare that they have no competing interests.

\section{Authors' contributions}

$\mathrm{RC}$ performed in vitro experiments and molecular analysis, OJB designed and set up immunohistochemical analysis, SR and CGM performed confocal microscopy experiments, OJB, VB, MP and JMR collected the data from the patients. JC and LB oversaw the manuscript. VLLC conceived the study, designed and prepared the manuscript. All authors read and approved the final manuscript.

\section{Acknowledgement}

The authors thank the continuous support of Laura Nasarre, Marta Sánchez and Ma Angeles Velasco. This work was funded by grants from Instituto de Salud Carlos III, REDINSCOR RD06/003/0000 (J. Cinca), RD06/0003/0015 (V. Llorente-Cortés and O. Juan-Babot), RD06/0003/1001 (M. Portoles and J Rivera), FIS PI11/00747 cofinanced by Fondo Europeo de Desarrollo Regional (F.E.D.E.R) and by Fundació MARATÓ TV3 (080110). LB and VLLC are members of the international graduate program PROMISE (IRTG.1566).

\section{Author details}

${ }^{1}$ Cardiovascular Research Center, CSIC-ICCC, Hospital de la Santa Creu I Sant Pau, Sant Antoni Ma Claret, 167, 08025, Barcelona, Spain. ${ }^{2}$ Cardiology Service, IIB-Sant Pau. Hospital de la Santa Creu i Sant Pau, Universitat Autònoma de Barcelona, Barcelona, Spain. ${ }^{3}$ ICREC Research Program, Fundació Institut d'Investigació en Ciències de la Salut Germans Trias i Pujol (IGTP), Badalona, Spain. ${ }^{4}$ Research Center, Hospital Universitario La Fe, Valencia, Spain. ${ }^{5} \mathrm{CIBER}$ OBN, Instituto de Salud Carlos III, Cordoba, Spain.

Received: 3 July 2012 Accepted: 25 July 2012

Published: 8 August 2012

\section{References}

1. Chabowski A, Gorski J, Calles-Escandon J, Tandon NN, Bonen A: Hypoxiainduced fatty acid transporter translocation increases fatty acid transport and contributes to lipid accumulation in the heart. FEBS Lett 2006, 580:3617-3623.

2. Schaffer JE: Lipotoxicity: when tissues overeat. Curr Opin Lipido/ 2003, 1:281-287.

3. van Herpen NA, Schrauwen-Hinderling VB: Lipid accumulation in nonadipose tissue and lipotoxicity. Physiol Behav 2008, 94:231-241.

4. Goldfarb JW, Roth M, Han J: Myocardial fat deposition after left ventricular myocardial infarction: assessment by using MR water-fat separation imaging. Radiology 2009, 253:65-73.

5. Jodalen H, Stangeland L, Grong K, Vik-Mo H, Lekven J: Lipid accumulation in the myocardium during acute regional ischaemia in cats. J Mol Cell Cardiol 1985, 17:973-980.

6. Straeter-Knowlen IM, Evanochko WT, den Hollander JA, Wolkowicz PE, Balschi JA, Caulfield JB, Ku DD, Pohost GM: 1 H NMR spectroscopic 
imaging of myocardial triglycerides in excised dog hearts subjected to 24 hours of coronary occlusion. Circulation 1996, 93:1464-1470.

7. Listenberger LL, Han X, Lewis SE, Cases S, Farese RV, Ory DS, Schaffer JE: Triglyceride accumulation protects against fatty acid-induced lipotoxicity. Proc Natl Acad Sci 2003, 100:3077-3082.

8. Barba I, Chavarria L, Ruiz-Meana M, Mirabet M, Agulló E, Garcia-Dorado D: Effect of intracellular lipid droplets on cytosolic $\mathrm{Ca} 2+$ and cell death during ischaemia-reperfusion injury in cardiomyocytes. J Physiol 2009, 587:1331-1341.

9. $\quad$ van de Weijer T, Schrauwen-Hinderling VB, Schrauwen P: Lipotoxicity in type 2 diabetic cardiomyopathy. Cardiovas. Res. 2011, 92:10-18.

10. Young ME, Guthrie PH, Razeghi P, Leighton B, Abbasi S, Patil S, Youker KA, Taegtmeyer $\mathrm{H}$ : Impaired long-chain fatty acid oxidation and contractile dysfunction in the obese Zucker rat heart. Diabetes 2002, 51:2587-2595.

11. Fujita S, Terasaki F, Otsuka K, Katashima T, Kanzaki Y, Kawamura K, Tanaka T: Markedly increased intracellular lipid droplets and disruption of intercellular junctions in biopsied myocardium from a patient with arrhythmogenic right ventricular cardiomyopathy. Hear Vessel 2008, 23:440-444.

12. Castellano J, Farré J, Fernandes J, Bayes-Genis A, Cinca J, Badimon L, Hove-Madsen L, Llorente-Cortés V: Hypoxia exacerbates Ca(2+)-handling disturbances induced by very low density lipoproteins (VLDL) in neonatal rat cardiomyocytes. J Mol Cell Cardiol 2011, 50:894-902.

13. Fielding CJ: Metabolism of cholesterol-rich chylomicroms. Mechanism of binding and uptake of cholesteryl esters by the vascular bed of the perfused rat heart. J Clin Invest 1978, 62:141-151.

14. Pillutla P, Hwang YC, Augustus A, Yokoyama M, Yagyu H, Johnston TP, Kaneko M, Ramasamy R, Goldberg IJ: Perfusion of hearts with triglyceriderich particles reproduces the metabolic abnormalities in lipotoxic cardiomyopathy. Am J Physiol Endocrinol Metab 2005, 288:E1229-E1235.

15. Niu YG, Hauton D, Evans RD: Utilization of triacylglycerol-rich lipoproteins by the working rat heart: routes of uptake and metabolic fates. J Physiol 2004, 558:225-237

16. Perman JC, Boström $P$, Lindbom M, Lidberg U, StÅhlman M, Hägg D, Lindskog H, Scharin Täng M, Omerovic E, Mattsson Hultén L, Jeppsson A, Petursson P, Olivecrona HG, Strickland DK, Ekroos K, Olofsson SO, Borén J: The VLDL receptor promotes lipotoxicity and increases mortality in mice following an acute myocardial infarction. J Clin Invest 2011, 121:2625-2640.

17. Cal R, Castellano J, Revuelta-López E, Aledo R, Barriga M, Farré J, Vilahur G, Nasarre L, Hove-Madsen L, Badimon L, Llorente-Cortés V: Low density lipoprotein receptor-related protein 1 mediates hypoxia-induced VLDL-cholesteryl ester uptake and accumulation in cardiomyocytes. Cardiovasc Res 2012, 94:469-479.

18. Castellano J, Aledo R, Sendra J, Costales P, Juan-Babot O, Badimon L, Llorente-Cortés $V$ : Hypoxia stimulates low-density lipoprotein receptorrelated protein-1 expression through hypoxia-inducible factor-1alpha in human vascular smooth muscle cells. Arterioscler Thromb Vasc Biol 2011, 31:1411-1420

19. Llorente-Cortés V, Otero-Viñas M, Sánchez S, Rodríguez C, Badimon L: Lowdensity lipoprotein upregulates low-density lipoprotein receptor-related protein expression in vascular smooth muscle cells: possible involvement of sterol regulatory element binding protein-2-dependent mechanism. Circulation 2002, 106:3104-3110.

20. Swedberg K, Cleland J, Dargie H, Drexler H, Follath F, Komajda M, Tavazzi L, Smiseth OA, Gavazzi A, Haverich A, Hoes A, Jaarsma T, Korewicki J, Lévy S, Linde C, Lopez-Sendon JL, Nieminen MS, Piérard L, Remme WJ: Task Force for the Diagnosis and Treatment of Chronic Heart Failure of the European Society of Cardiology. Guidelines for the diagnosis and treatment of chronic heart failure: executive summary (update 2005): The Task Force for the Diagnosis and Treatment of Chronic Heart Failure of the European Society of Cardiology. Eur. Heart. J. 2005, 26:1115-1140.

21. Llorente-Cortés V, Martínez-González J, Badimon L: LDL receptor-related protein mediates uptake of aggregated LDL in human vascular smooth muscle cells. Arterioscler Thromb Vasc Biol 2000, 20:1572-1579.

22. Llorente-Cortés V, Otero-Viñas M, Hurt-Camejo E, Martínez-González J, Badimon L: Human coronary smooth muscle cells internalize versicanmodified LDL through LDL receptor-related protein and LDL receptors. Arterioscler Thromb Vasc Biol 2002, 22:387-393.

23. Llorente-Cortés V, Otero-Viñas M, Camino-López S, Costales P, Badimon L: Cholesteryl esters of aggregated LDL are internalized by selective uptake in human vascular smooth muscle cells. Arterioscler Thromb Vasc Biol 2006, 26:117-123.

24. Costales P, Aledo R, Vérnia S, Das A, Shah VH, Casado M, Badimon L, Llorente-Cortés $\mathrm{V}$ : Selective role of sterol regulatory element binding protein isoforms in aggregated LDL-induced vascular low density lipoprotein receptor-related protein-1 expression. Atherosclerosis 2010, 213:458-468.

25. Llorente-Cortés V, Costales P, Bernués J, Camino-Lopez S, Badimon L: Sterol regulatory element-binding protein-2 negatively regulates low density lipoprotein receptor-related protein transcription. J Mol Biol 2006, 359:950-960.

26. Sendra J, Llorente-Cortés V, Costales P, Huesca-Gómez C, Badimon L: Angiotensin II upregulates LDL receptor-related protein (LRP1) expression in the vascular wall: a new pro-atherogenic mechanism of hypertension. Cardiovasc Res 2008, 78:581-589.

27. Glenn DJ, Wang F, Nishimoto M, Cruz MC, Uchida Y, Holleran WM, Zhang Y: Yeghiazarians and D.G. Gardner. A murine model of isolated cardiac steatosis leads to cardiomyopathy. Hypertension 2011, 57:216-222.

28. Liu L, Zhang Y, Chen N, Shi X, Tsang B, Yu YH: Upregulation of myocellular DGAT1 augments triglyceride synthesis in skeletal muscle and protects against fat-induced insulin resistance. J Clin Invest 2007, 117:1679-1689.

29. Hamilton JA, Kamp F: How are free fatty acids transported in membranes? Is it by proteins or by free diffusion through the lipids? Diabetes 1999, 48:2255-2269.

30. Merkel M, Heeren J, Dudeck W, Rinninger F, Radner H, Breslow JL, Goldberg IJ, Zechner R, Greten H: Inactive lipoprotein lipase (LPL) alone increases selective cholesterol ester uptake in vivo, whereas in the presence of active LPL it also increases triglyceride hydrolysis and whole particle lipoprotein uptake. J Biol Chem 2002, 277:7405-7411.

31. Augustus AS, Kako Y, Yagyu H, Goldberg IJ: Routes of FA delivery to cardiac muscle: modulation of lipoprotein lipolysis alters uptake of TGderived FA. Am J Physiol Endocrinol Metab 2003, 284:E331-339.

32. Huang Y, Walker KE, Hanley F, Narula J, Houser SR, Tulenko TN: Cardiac systolic and diastolic dysfunction after a cholesterol-rich diet. Circulation 2004, 109:97-102.

33. Osipov RM, Bianchi C, Feng J, Clements RT, Liu Y, Robich MP, Glazer HP, Sodha NR, Sellke FW: Effect of hypercholesterolemia on myocardial necrosis and apoptosis in the setting of ischemia-reperfusion. Circulation 2009, 120(11 Suppl):S22-S30.

34. Ronkainen VP, Skoumal R, Tavi P: Hypoxia and HIF-1 suppress SERCA2a expression in embryonic cardiac myocytes through two interdependent hypoxia response elements. J Mol Cell Cardiol 2011, 50:1008-1016.

doi:10.1186/1479-5876-10-160

Cite this article as: Cal et al: Low density lipoprotein receptor-related protein 1 expression correlates with cholesteryl ester accumulation in the myocardium of ischemic cardiomyopathy patients. Journal of Translational Medicine 2012 10:160.

\section{Submit your next manuscript to BioMed Central and take full advantage of:}

- Convenient online submission

- Thorough peer review

- No space constraints or color figure charges

- Immediate publication on acceptance

- Inclusion in PubMed, CAS, Scopus and Google Scholar

- Research which is freely available for redistribution 